\title{
- Ovário salpingo histerectomia em cadelas e gatas - proposta de novos procedimentos
}

\section{- Ovarysalpingohisterectomy in bitches and queens: a new procedure is proposed}

*Mr. Cão Pet Complex Rua Major Prado, 42 CEP: 04517-020 - São Paulo, SP. Fone: $\left(0^{\star \star} 11\right) 535-6642$ 5096-6234

e-mail: dr roney vet@aol.com

\footnotetext{
* Roney Migliari' ${ }^{1}$ CRMV-SPn ${ }^{0} 5849^{\text {+(inmemorian) }}$

Rafael Struffaldi De Vuono ${ }^{2}$ - CRMV-SPn ${ }^{0} 10497$

1 Médico Veterinário

"Mr. Cão Pet Complex"

2 Professor Auxiliar - Disciplina de Técnica Cirúrgica e Anestesiologia da UNIBAN - Mestrando do Departamento de Cirurgia da FMVZ - USP
}

\section{RESUMO}

A ovário salpingo histerectomia é a cirurgia eletiva mais procurada nas clínicas e hospitais veterinários de pequenos animais. A técnica aqui exposta permite a redução do tempo cirúrgico, da quantidade de instrumentos cirúrgicos utilizados e do tempo de recuperação dos pacientes, levando a significativa redução no custo da cirurgia, sendo perfeitamente possível a um cirurgião operar mais de cinco animais por hora. Tendo empregado esta técnica nos últimos dois anos, submetendo mais de 3.000 animais a tal procedimento, constatamos resultados melhores dos que os obtidos quando utilizávamos as técnicas tradicionais.

Palavras-chave: cães, gatos, ovário salpingo histerectomia.

\section{Introdução}

aumento da população animal e a adequada conscientização da população sobre a necessidade do correto controle de natalidade em animais domésticos vem tornando a ovário salpingo histerectomia a cirurgia mais realizada em nossas clínicas. Em outros países já existem centros cirúrgicos, onde são realizadas exclusivamente cirurgias de esterilização, tanto de machos como de fêmeas, mediante programa especial. Cabe lembrar que esta cirurgia, além de ser o tratamento usual para muitas das afecções ovarianas e uterinas, também é indicada para a prevenção de recidiva de hiperplasia de vagina, bem como para animais diabé- ticos ou epilépticos, para que sejam evitadas as alterações hormonais capazes de interferir na terapêutica (SLATTER, 1998).

Apesar de ser procedimento cirúrgico aplicável em qualquer idade, se esta cirurgia for realizada antes do primeiro ciclo ovariano, a incidência de neoplasias de glândulas mamárias diminui para menos que $0,5 \%$. Já, logo após o primeiro cio, o risco aumenta para $8 \%$; depois de dois ciclos, sobe para $26 \%$, e depois dos dois anos e meio de idade não se tem mais este efeito (SCHNEIDER, et al., 1969). Gatas intactas apresentam risco sete vezes maior de neoplasia mamária, em comparação com fêmeas ovariectomizadas (DORM, et al., 1969). Em contrapartida, se realizada de forma muito 
precoce, antes do término da vacinação, estaremos expondo os animais ao risco de contrair doenças infecciosas, em razão do baixos níveis de imunidade que poderão portar.

\section{Materiais e Métodos Considerações iniciais}

Em dezembro de 1997, introduzimos a técnica ora proposta em nossa clínica, com o objetivo de dispensar a figura do auxiliar de cirurgião, baixar o tempo total de cirurgia e diminuir os gastos com anestésicos. Dessa forma, otimizando-se a utilização da sala de cirurgia, eliminando-se os retornos pós-operatórios e reduzindo-se a quantidade de material e instrumentos utilizados, com conseqüente redução no custo da cirurgia.

Após termos submetido à cirurgia um número superior a 3.000 fêmeas com constantes aperfeiçoamentos, a experiência mostrou-nos que a técnica abaixo descrita exige anestesia geral, com elevado grau de miorelaxamento; posicionamento do animal em decúbito supino em uma calha, sem a necessidade de conter-se os membros com amarras (principalmente os pélvicos), diminuindo, com isso, a tensão sobre a musculatura do abdome e reduzindo a tração necessária para expor o ovário. Ainda, é necessário que se mantenha a mesa com uma inclinação, de tal forma que a pélvis fique mais elevada e o conteúdo abdominal gravite em direção cranial, facilitando bastante o acesso (posição "Trendelemburg”). Embora essa posição desloque as vísceras abdominais em direção cranial, não observamos qualquer comprometimento respiratório decorrente de compressão sobre o músculo diafragma. Não menos importante, temos ainda que efetuar o esvaziamento da vesícula urinária, a fim de facilitar a localização dos cornos uterinos.

\section{Instrumental cirúrgico}

1 pinça dente de rato
3 pinças "Crile"
1 cabo de bisturi
1 porta agulhas Egard-Olsew
1 gancho de ováriohisterectomia

\section{Anatomia topográfica cirúrgica}

Os ovários, as tubas, os cornos e o útero são presos às paredes dorsolaterais da cavidade abdominal e à parede lateral da cavidade pélvica, por meio de

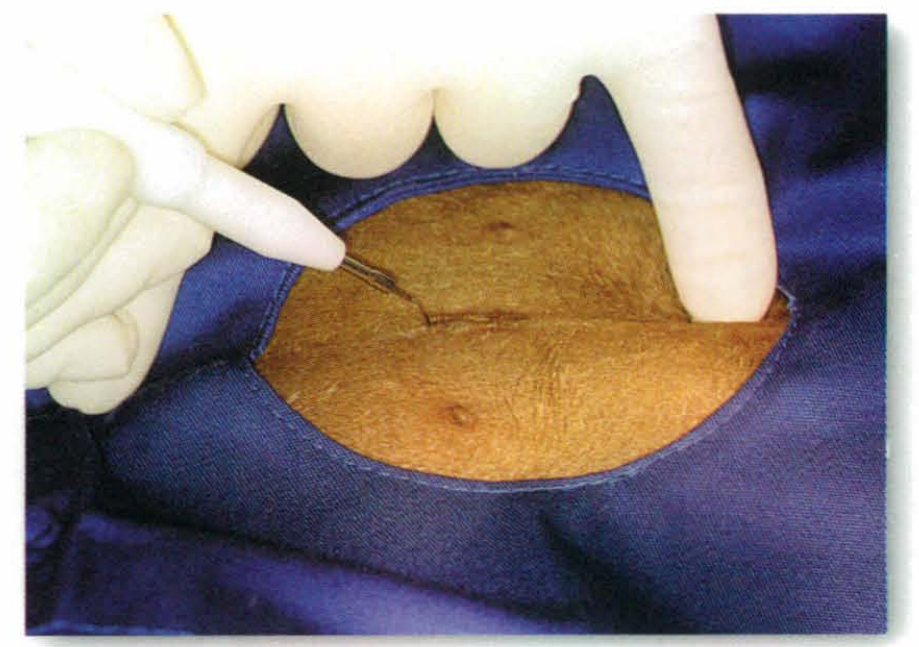

Figura 1. Realização da incisão de pele, no ponto eqüidistante entre a cicatriz umbilical e o púbis (em gatas a incisão é feita caudalmente a esse ponto).

pregas duplas pareadas do peritônio, chamadas de mesos, que se dividem em três regiões: o mesovário, a mesossalpinge e o mesométrio (ligamentos largos, direito e esquerdo); cranialmente unem-se ao ligamento suspensor do ovário. O ligamento suspensor do ovário corre da face ventral do ovário e da mesossalpinge, cranial e dorsalmente para os terços médios e ventrais das duas últimas costelas (FARTON e WITHOROWS, 1981). O ligamento próprio, que é a continuação caudal do ligamento suspensor do ovário, prende-se à extremidade cranial do corno uterino. O ligamento redondo do útero prende-se à extremidade cranial do corno uterino e é a continuação caudal do ligamento próprio. O ligamento redondo estende-se caudal e ventralmente ao ligamento largo e, na maioria das cadelas, passa através do canal inguinal e termina subcutaneamente próximo à vulva (EVANS e CHRISTENSEN, 1981).

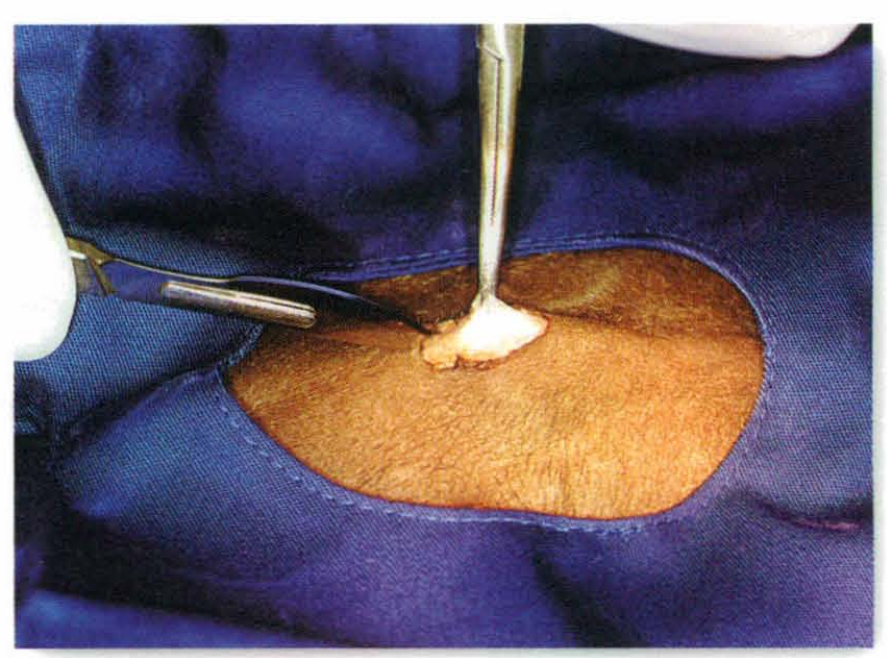

Figura 2. Realização da incisão da parede abdominal com a lâmina de bisturi voltada para cima. 


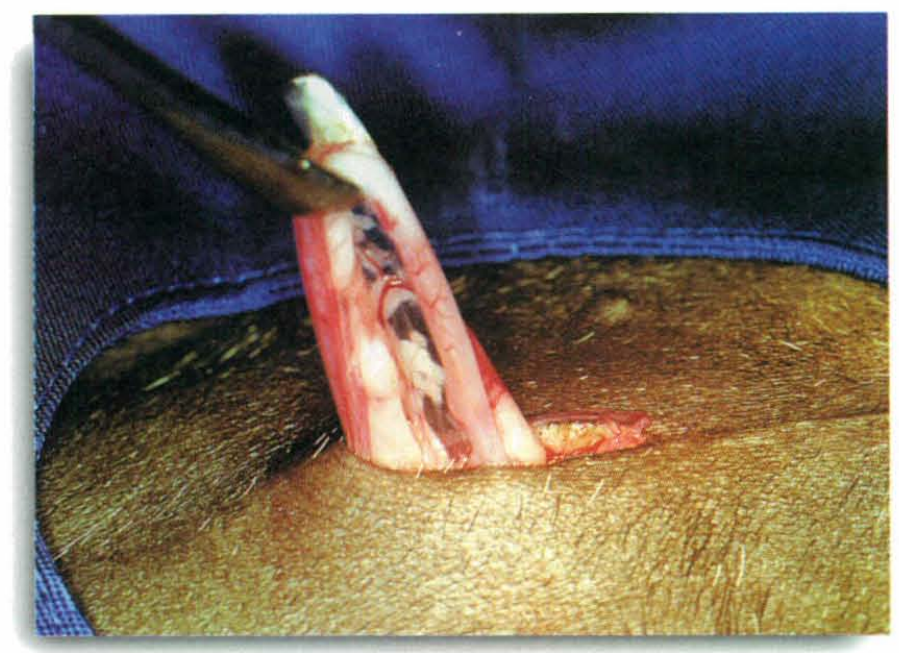

Figura 3. Exteriorização do corno uterino com a utilização do gancho de ováriohisterectomia.

O complexo artério-venoso ovariano repousa sobre o lado medial do ligamento largo e estende-se da aorta para o ovário. A artéria ovariana supre o ovário. Existem pequenas anastomoses no ligamento largo entre os ramos da artéria ovariana e os ramos da artéria uterina.

A veia ovariana esquerda drena para o interior da veia renal esquerda, e a veia ovariana direita drena para o interior da veia cava caudal (DELCAMPO e GUINTHER, 1974). As veias uterinas correm em associação íntima com as artérias uterinas e terminam caudalmente nas veias ilíacas internas.

\section{Técnica cirúrgica proposta}

Considerando-se as particularidades da anatomia topográfica cirúrgica acima descrita, a incisão da pele deve ser realizada na linha média, tomando como referência o ponto eqüidistante entre a cicatriz umbilical e o púbis. Nas cadelas, pelo fato de os pedículos ovarianos nesta espécie serem curtos, dificultando sua exteriorização, e o corpo uterino longo, a incisão será feita cranialmente a este ponto (variando de $1 \mathrm{~cm}$ a $5 \mathrm{~cm}$ de comprimento em função do porte e raça do animal), enquanto que nas gatas, em função de as condições anatômicas serem inversas às da cadela, a incisão será caudal ao ponto indicado anteriormente (variando de $1 \mathrm{a} 2 \mathrm{~cm}$ ), pois, nesse caso, o corpo uterino é de mais difícil exteriorização e os pedículos ovarianos apresentam-se mais longos. Se o útero e ou os ovários estiverem aumentados, a incisão deverá ser alongada (Figura 1).

Após pequena divulsão do tecido celular subcutâneo, o suficiente para se visualizar a linha alba, faz-se a invasão da cavidade abdominal. Com o auxílio de uma

\footnotetext{
I Nailon monofilamentado $\mathrm{n}^{\circ} 1$ - Brasmédica Ltda.

2 Nikrothal $80-n^{\circ}$ B\&S 31.000 - Kantal do Brasil Ltda.
}

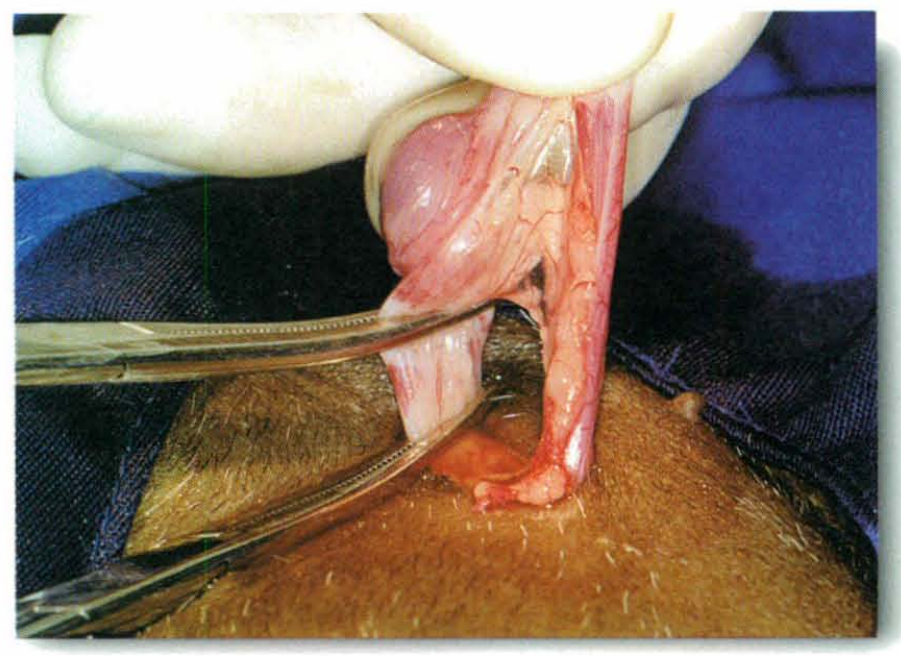

Figura 4. Aplicação das pinças "Crile" no pedículo ovariano.

pinça dente de rato ou "Crile", suspende-se a parede abdominal pela linha alba e introduz-se a lâmina do bisturi voltada para cima, realizando-se incisão pequena o suficiente para a exteriorização dos ovários. Caso se faça necessário, com um pinça "Crile", faz-se a divulsão da mesma, a fim de se ter uma abertura maior (Figura 2).

O corno uterino esquerdo deverá ser localizado e exteriorizado com a ajuda do gancho de ovariohisterectomia, introduzindo-se o gancho rente à parede abdominal e fazendo-se um movimento pendular em direção ao acetábulo (a inclinação do gancho será idêntica à do ponteiro menor do relógio, às 5 horas), evitando-se o baço e a vesícula urinária (Figura 3). Para se exteriorizar o ovário, traciona-se levemente o corno uterino com o auxílio de compressa, mantendo o ovário seguro pelo dedo médio e polegar, e, com o dedo indicador, abre-se uma "janela" no mesovário, caudalmente ao complexo artériovenoso ovariano. O pedículo será pinçado com duas pinças "Crile" que deverão distar o máximo possível uma da outra; a pinça colocada mais distante do ovário deverá ser rotacionada sobre seu eixo maior com a finalidade de inspecionar a possibilidade de haver qualquer outra estrutura pinçada juntamente com o pedículo (Figura 4). O pedículo será seccionado entre as duas pinças e o corno uterino rebatido sobre o coxal. Passando-se o fio sob a pinça, efetua-se a ligadura do pedículo; nas cadelas utilizando fio mononylon $\mathrm{n}^{\circ} 1^{1}$, dando nó de cirurgião bem firme, e, nas gatas, fio níquel-cromo ${ }^{2}$ com $0,2 \mathrm{~mm}$ com um nó simples (Figura 5). O pedículo será, em seguida, cuidadosamente reposicionado no interior do abdome $\mathrm{e}$ só então a pinça será removida. O procedimento é repetido no pedículo ovariano oposto (Figura 6).

Ato contínuo, exterioriza-se, então, o corpo uterino, protegendo-se a artéria e a veia uterinas, faz-se uma 
"janela" no mesométrio e, com o bisturi, vem se dissecando o mesmo até seccionar o ligamento largo direito e esquerdo. Uma única pinça "Crile" é colocada no mesmo, cerca de $5 \mathrm{~mm}$ acima da cérvix (Figura 7). Nos casos de úteros graví-
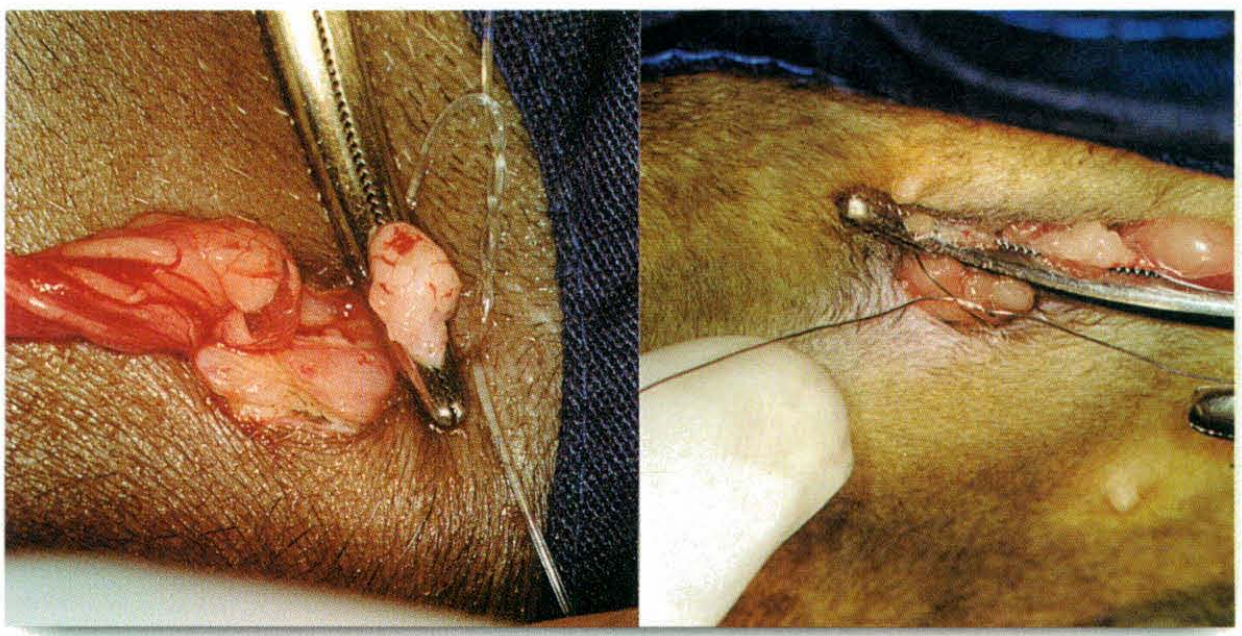

Figura 5. Ligadura dos pedículos ovarianos, à esquerda em cadela com fio mononylon, à direita em gata com fio níquel-cromo. dicos ou aumentados, realiza-se a ligadura antes de seccioná-los; nos casos dos úteros que se encontram em anestro e sem patologia, secciona-se o corpo uterino cerca de $5 \mathrm{~mm}$ acima da pinça, passando-se o fio sob a pinça, posicionando-o imediatamente acima da cérvix, fazse um nó duplo, voltando as pontas do fio para o lado oposto, concluindo-se com nó de cirurgião. Nas gatas que se encontram no anestro e com o útero normal, pode-se fazer a ligadura com fio de níquel-cromo com um nó verdadeiro, tomando-se o cuidado de manter o nó na face dorsal do coto. Cuidadosamente, o coto uterino é reposicionado dentro do abdome e a pinça é removida.

Pode-se utilizar uma pequena pinça hemostática para segurar pedículo e coto acima das pinças "Criles", abrindo-se com cuidado esta última; verificar se está ocorrendo hemorragia, antes de recolocar essas estruturas dentro da cavidade abdominal.

Utilizando fio níquel-cromo $0,2 \mathrm{~mm}$, efetuamos a sutura da parede abdominal com ponto "Sultan" (X) (Figura 8) e na pele pontos intradérmicos em "Ü" (Figura 9). Caso o cirurgião entenda necessário, pode utilizar adesivo cirúrgico à base de cianoacrilato, para obter melhor coaptação das bordas da pele.

\section{Resultados e Discussão}

Após dois anos da utilização desta técnica, com mais de 3000 fêmeas operadas, verificou-se que o tempo total de cirurgia caiu substancialmente, quando comparado ao tempo trans-operatório das técnicas tradicionais, diminuindo o consumo de anestésico por cirurgia; dispensou-se o cirurgião auxiliar, possibilitando montar uma rotina que viabilizou economicamente a

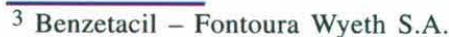

logo após a cirurgia, permitiu eliminar os retornos pósoperatórios. A reduzida quantidade de material e instrumental utilizados associados aos demais fatores acima expostos resultaram na diminuição no custo total da cirurgia, o que a torna acessível para um espectro mais amplo das camadas da população.

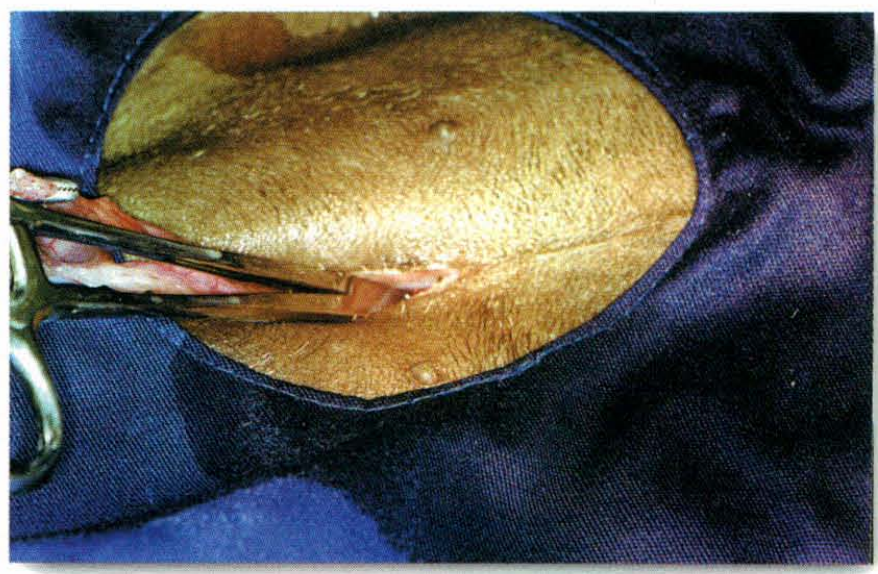

Figura 6. Reposicionamento do pedículo ovariano no seu local anatômico.

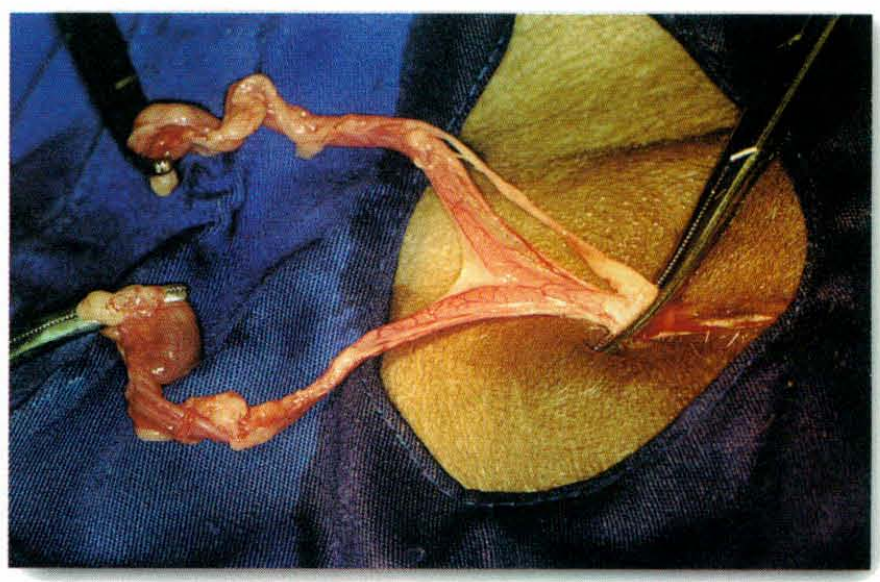

Figura 7. Aplicação da pinça em coto uterino.

sala de cirurgia, possível um cirurgião operar até 10 animais no período da manhã. A incisão de pequena extensão, o tipo e o fio de sutura, somados a uma única administração de antibioticoterapia (penicilina benzatina ${ }^{3}$ ) . (n) 


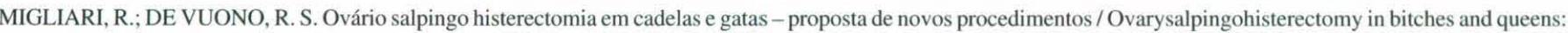
a new procedure is proposed. / Rev. educ. contin. CRMV-SP / Continuous Education Journal CRMV-SP, São Paulo, volume 3, fascículo 3, p. 028 - 032, 2000.

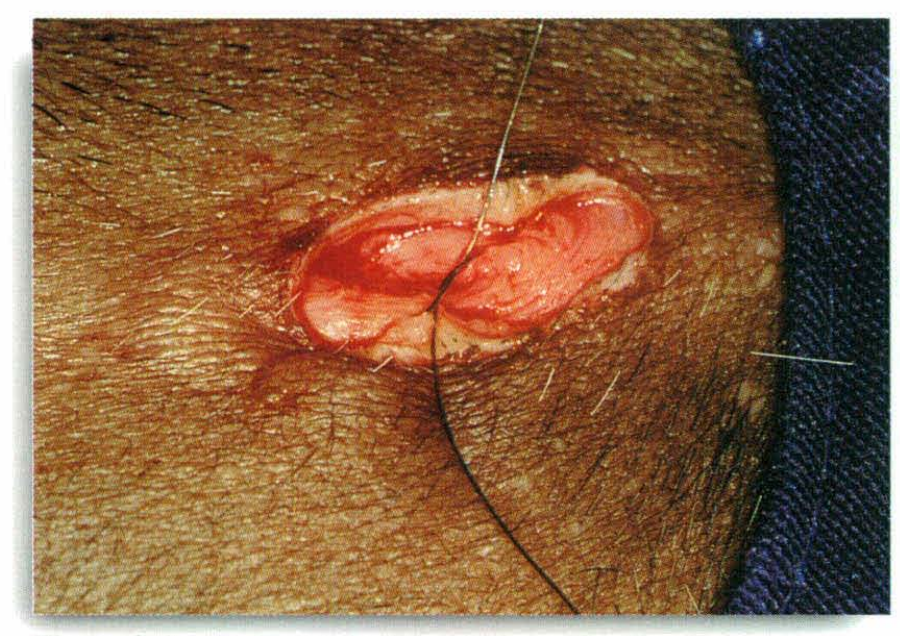

Figura 8. Sutura da parede abdominal com fio níquel-cromo.

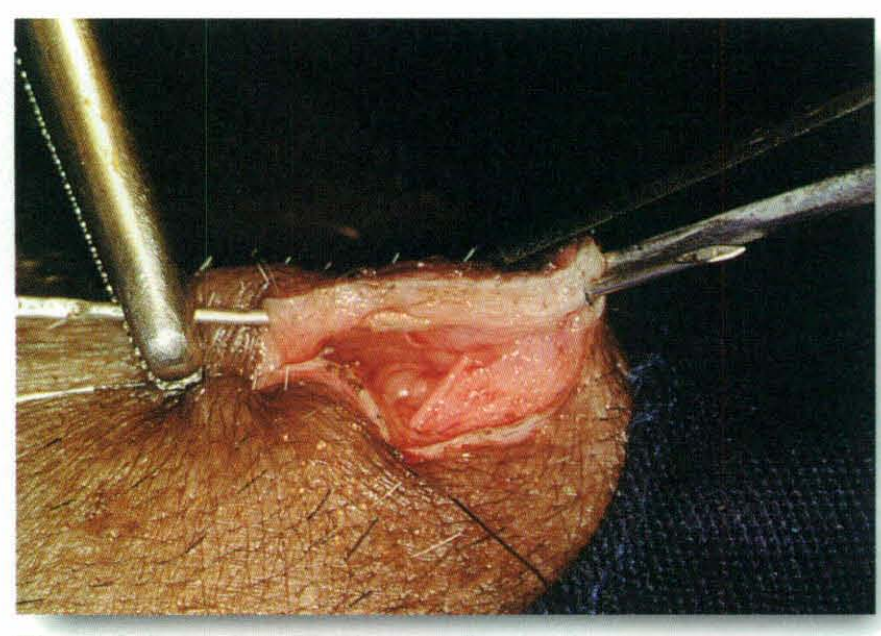

Figura 9. Sutura intradérmica com fio níquel-cromo.

\section{SUMMARY}

Ovarysalpingohisterectomy is the elective surgery most often performed in veterinary practices and hospitals for companion animals. The technique here described reduces the time of surgery, the number of surgical instruments needed and time for recovery of patients, resulting in a significant reduction in the cost. It also enables the surgeon to perform up five surgeries or more per hour. Having used this technique in the last two years, the author performed the procedure in over 3,000 animals, results being better than those obtained with the traditional techniques.

Key words: dogs, cats, hysterectomy.

\section{HOMENAGEM}

Além da contribuição científica, com a publicação deste trabalho a Comissão Editorial da Rev. educ. contin. CRMV-SP presta um tributo à memória do colega e amigo Roney Migliari.

\section{REFERÊNCIAS BIBLIOGRÁFICAS}

1 - BOJRAB, M.J. Técnicas atuais em cirurgia de pequenos animais, 3.ed, São Paulo: Roca, p. 375-8, 1996.

2 - DELCAMPO, C.H.; GINTHER, O.J. Arteries and veins of uterus and ovaries in dogs and cats. American Journal of Veterinary Research, v. 35, n.3, p.409, 1974.

3 - DORM, C.R. et al. Survey of animal neoplasia in Alameda and Contra Costa Counties, Calif. II Cancer morbidity in dogs and cats from Alameda County. Journal of the National Cancer Institute, n.40, p.307, 1969.

4 - EVANS, H.E.; CHRISTENSEN, G.C. Miller's anatomy of the dog. 2. ed. Philadelphia: WB. Saunders, 1981.
5 - FARTON, J.W.; WITHOROWS, S.J.: Canine mammary neoplasias: an overview. California Veterinary, n.7, p.12, 1981.

6 - LEONARD, E.P. Cirurgia de pequeños animales. Barcelona: Cientifico-Médica, 1972, p. 239-41.

7 - SCHNEIDER R, et al. Factors influencing canine mammary cancer development and post surgical survival. Journal of American Veterinary Medical Assocciation, n.159, p.1780, 1969.

8 - SLATTER, D. Manual de cirurgias de pequenos animais. 2. ed, São Paulo: Manole, 1998, v. 2, p. 1553. 